\title{
Diklofenak'ın Fotokimyasal İleri Oksidasyon Prosesleri ile Arıtılabilirliğinin Araştırılması
}

\author{
Sevda HATUN ALTIN ${ }^{1 \mathrm{a}}$, Sevde ÜSTÜN ODABAŞI ${ }^{1{ }^{1{ }^{*}}}$, Hanife BÜYÜKGÜNGÖR ${ }^{1 \mathrm{c}}$ \\ ${ }^{1}$ Ondokuz Mayıs Üniversitesi, Mühendislik Fakültesi, Çevre Mühendisliği Bölümü. 55200 Samsun, Türkiye \\ sevde.ustun@omu.edu.tr
}

\begin{abstract}
Received/Geliș: 13.05.2020
Accepted/Kabul: 29.06.2020

Öz: Bu çalı̧̧ada seçilen ilaç, antienflamatuar yapıya sahip ilaçlar içerisinde en yüksek akut toksisitesi bulunan diklofenak ilacıdır. Arıtım yöntemlerinden $\mathrm{UV}$ ve kombinasyonları $\left(\mathrm{UV} / \mathrm{H}_{2} \mathrm{O}_{2}, \mathrm{UV} / \mathrm{TiO} \mathrm{O}_{2}, \mathrm{UV} / \mathrm{ZnO}\right)$ çalışılmıştır. Diklofenak içeren sentetik suyun $\mathrm{UV}, \mathrm{UV} / \mathrm{H}_{2} \mathrm{O}_{2}, \mathrm{UV} / \mathrm{TiO}_{2}$ ve $\mathrm{UV} / \mathrm{ZnO}$ yöntemleri ile 0-10-20-30-40-5060.dakikalarda numune alınarak giderimi incelenmiștir. $\mathrm{UV} / \mathrm{H}_{2} \mathrm{O}_{2}$ prosesi için $50,100,200,400,800 \mathrm{mg} / \mathrm{L}$ konsantrasyonlarında, $\mathrm{UV} / \mathrm{TiO}_{2}$ ve UV/ZnO prosesleri için ise $40,80,160,240,320 \mathrm{mg} / \mathrm{L}$ konsantrasyonlarında farklı diklofenak çözeltileri hazırlanmıştır. Çalışmada diklofenak konsantrasyonları Sıvı Kromatografi Tandem Kütle Spektrometresi (LC-MS/MS) ve organik kirlilik ise Toplam Organik Karbon (TOK) cihazları ile ölçülmüşșiur. Tüm proseslerde çalışma koşulları aynı kalmıştır. LCMS/MS analizinde UV prosesi için diklofenak giderim verimi $\% 55,23, \mathrm{UV} / \mathrm{H}_{2} \mathrm{O}_{2}$ ile diklofenak giderimi ise $200 \mathrm{mg} / \mathrm{L} \mathrm{H}_{2} \mathrm{O}_{2}$ konsantrasyonunda \% $>99,99$ bulunmuştur. TOK giderimi UV proseste $\% 30,71, \mathrm{UV} / \mathrm{H}_{2} \mathrm{O}_{2}$ prosesinde ise en yüksek verim $800 \mathrm{mg} / \mathrm{L}$ 'de $\% 97$ olarak bulunmuştur. UV/TiO ${ }_{2}$ ve UV/ZnO prosesi sonucunda TOK giderimi $320 \mathrm{mg} / \mathrm{L}$ 'de sirasıyla $\% 93,23$ ve $\% 96,10$ bulunmuştur. LC-MS/MS analiz sonuçlarında ise $240 \mathrm{mg} / \mathrm{L} \mathrm{TiO}_{2}$ ve $\mathrm{ZnO}$ konsantrasyonlarında diklofenak giderimi \%>99,99 olarak bulunmuştur. Sonuçlara göre UV prosesinin tek başına etkinliği \%10-30 iken $\mathrm{UV} / \mathrm{ZnO}, \mathrm{UV} / \mathrm{TiO}_{2}, \mathrm{UV} / \mathrm{H}_{2} \mathrm{O}_{2}$ gibi kombinasyonlarında daha etkili giderim verimi $(\% 60->99,99)$ elde edilmiştir. Maliyet açısından ise optimum proses $\mathrm{UV} / \mathrm{H}_{2} \mathrm{O}_{2}(200 \mathrm{mg} / \mathrm{L})$ prosesi bulunmuştur.
\end{abstract}

Anahtar Kelimeler: Atıksu; Diklofenak, İleri oksidasyon prosesleri; LCMS/MS; TOK.

\section{Investigation of The Treatability of Diclofenac by Photochemical Advanced Oxidation Processes}

\begin{abstract}
The drug selected in this study is diclofenac which has the highest acute toxicity among all of the antiinflammatory drugs. In this study, UV was integrated with different oxidants $\left(\mathrm{UV} / \mathrm{H}_{2} \mathrm{O}_{2}, \mathrm{UV} / \mathrm{TiO}_{2}, \mathrm{UV} / \mathrm{ZnO}\right)$, to study the removal efficiency of diclofenac. Synthetic wastewater containing diclofenac drug were treated with the help of $\mathrm{UV}, \mathrm{UV} / \mathrm{H}_{2} \mathrm{O}_{2}, \mathrm{UV} / \mathrm{TiO}_{2}$ and $\mathrm{UV} / \mathrm{ZnO}$ methods by taking samples at different time intervals of 0-1020-30-40-50-60 minutes. Different solutions of diclofenac were prepared with concentrations of, $50 \mathrm{mg} / \mathrm{L}$, $>99.99 \mathrm{mg} / \mathrm{l}, 200 \mathrm{mg} / \mathrm{L}, 400 \mathrm{mg} / \mathrm{L}$ and $800 \mathrm{mg} / \mathrm{L}$ for treated with $\mathrm{UV}$ and $\mathrm{UV} / \mathrm{H}_{2} \mathrm{O}_{2}$ for $\mathrm{UV} / \mathrm{TiO}_{2}$ and $\mathrm{UV} / \mathrm{ZnO}$ solutions were prepared with concentrations $40,80,160,240$ and $320 \mathrm{mg} / \mathrm{L}$. Diclofenac concentration was analyzed by Liquid Chromatography Mass Spectrometry (LCMS/MS) and organic pollutants were analyzed by Total Organic Carbon (TOK) device. The other operating conditions remained the same in all systems. In case of $200 \mathrm{mg} / \mathrm{L}$, LC-MS/MS analysis showed UV removal efficiency was $55.23 \%$ and $\mathrm{UV} / \mathrm{H}_{2} \mathrm{O}_{2}$ removal was $>99.99 \%$. TOC results showed that $30.71 \%$ diclofenac removal with UV and $97 \%$ with $\mathrm{UV} / \mathrm{H}_{2} \mathrm{O}_{2}$ removal, in case of $800 \mathrm{mg} / \mathrm{L}$ concentration. In case of $320 \mathrm{mg} / \mathrm{L}$, TOC analysis showed that $\mathrm{UV}^{-\mathrm{TiO}_{2}}$ and $\mathrm{UV} / \mathrm{ZnO}$ processes removal efficiency were respectively $93.23 \%$ and $96.10 \%$. LC-MS/MS analysis results showed that $>99.99 \%$ removal efficiency at $240 \mathrm{mg} / \mathrm{L}$ in both of $\mathrm{TiO}_{2}$ and $\mathrm{ZnO}$ concentrations. According to the results, while the effectiveness of the UV process alone is $10-30 \%$, more effective removal efficiency (\%60->99.99) was obtained in combinations such as $\mathrm{UV} / \mathrm{ZnO}, \mathrm{UV} / \mathrm{TiO}_{2}, \mathrm{UV} / \mathrm{H}_{2} \mathrm{O}_{2}$. In terms of cost, optimum process $\mathrm{UV} / \mathrm{H}_{2} \mathrm{O}_{2}$ $(200 \mathrm{mg} / \mathrm{L})$ process was found.
\end{abstract}

Keywords: Wastewater; Diclofenac; Advanced oxidation processes; LCMS-MS, TOC.

Altın, S.H., Üstün Odabaşı S., Büyükgüngör H., “Diklofenak'ın Fotokimyasal İleri Oksidasyon Prosesleri ile Arıtılabilirliğinin Araştırllması” El-Cezerî Fen ve Mühendislik Dergisi 2020, 7(3); 1110-1121. 


\section{Giriş}

Diklofenak, kullanımı yaygın olan non-sterodial anti-inflamatuar ağrı kesici grubunda bulunmaktadır [1]. Bu farmasötik; oral yoldan, enjeksiyon şeklinde ve krem olarak yaygın şekilde kullanılmaktadır. Diklofenak vücuda alındıktan sonra biyotransformasyon sonucu, oluşan metabolitleri ve \% 1'den az miktarı değişmeyen molekül biçimiyle idrarla atılır. Geri kalan kısım ise dışkıyla atılmaktadır [2].

Diklofenak antienflamatuar yapıya sahip kimyasallar içerisinde en yüksek akut etkiye sahip kimyasal olması nedeniyle çevresel risk açısından büyük önem taşımaktadır [3]. Yapılan çalışmalarda, balıklarda gözlemlenen en düşük etki konsantrasyonu (LOEC) değeri; $1 \mu \mathrm{g} / \mathrm{L}$ diklofenak konsantrasyonu olduğunda karaciğer, böbrek ve solungaç hücrelerinde değişimler ve LOEC değeri $5 \mu \mathrm{g} / \mathrm{L}$ olduğunda böbrek dokusunda bozulmalar ve solungaç yapılarında değişimler rapor edilmiştir [4]. 0,01-10 mg/L diklofenak konsantrasyonuna maruz kalan balıklarda yumurtadan çıkma sürecinde gecikme ve başarısızlık gözlenmiştir [5].

Kanalizasyon sistemine ulaşan ilaç kalıntılarının, özellikle diklofenağın, klasik atıksu arıtma tesislerinde giderimi tam olarak gerçekleşmemektedir [6,7]. Ülkemizde diklofenağın Yerüstü Su Kalitesi Yönetmeliği'ne göre nehirler, göller, kıyı ve geçiş sularında $100 \mu \mathrm{g} / \mathrm{L}$ altında olması gerekmektedir [8]. Bu nedenle diklofenak kalıntılarının atıksu arıtma tesislerinden alıcı ortama deşarjlarında belirlenen limit değerin altına düşürülmesi gereklidir. Bu tür kirleticilerin gideriminde konvansiyonel metotlar yetersiz kalacağı için ileri arıtım proseslerinden (İOP) yardım alınması gerekmektedir. Son zamanlarda yapılan çalışmalarda farmasötiklerin İOP'leri ile giderimi artış göstermektedir [9,10] Bunun en önemli sebebi; farmasötiklerin arıtılırken parçalanması, bazı durumlarda bozunma yan ürünlerinin orijinal üründen daha fazla biyolojik olarak bozunması ve daha az toksik olmasıdır. $\mathrm{Bu}$ nedenle İOP'leri biyolojik bir işlem sonrasında rahatça uygulanabilmektedir [11]. Kimyasal ve biyolojik proseslere göre İOP'lerinin en önemli avantaj1; kimyasal çöktürme, adsorpsiyon, uçurma gibi işlemlerle kirleticiyi başka bir faza aktarmaması aksine kirleticiyi tamamen mineralizasyona uğratarak, $\mathrm{CO}_{2}$ ve $\mathrm{H}_{2} \mathrm{O}$ gibi son ürünlere dönüştürmesidir [12]. Farmasötiklerin giderimde yaygın olarak kullanılan İOP'ler arasında, Ozon/Hidrojen peroksit, Ozon/Ultraviyole, Hidrojen peroksit/Ultraviyole, Ozon/Hidrojen peroksit/Ultraviyole prosesleri, Fenton prosesi, Foto-Fenton prosesi, heterojen Fenton sistemleri, fotokataliz yöntemleri bulunmaktadır [13].

$\mathrm{Bu}$ çalışmanın amacı, konvansiyonel sistemlerle tam olarak giderimi gerçekleşmeyen diklofenağın ileri oksidasyon proseslerinden sadece $\mathrm{UV}, \mathrm{UV} / \mathrm{H}_{2} \mathrm{O}_{2}, \mathrm{UV} / \mathrm{TiO}_{2}$ ve $\mathrm{UV} / \mathrm{ZnO}$ prosesleri ile giderim verimlerini karşılaştırmaktır. Giderim verimleri Sıvı Kromatografi Tandem Kütle Spektrometresi (LCMS/MS) ve Toplam Organik Karbon (TOK) cihazları ile belirlenmiştir. Ayrıca diklofenağın bu proseslerle bozunmasına ilişkin kinetik hesaplamalar yapılmış ve optimum prosesin tespiti için maliyet hesaplamaları da yapılmıştır.

\section{Materyal ve Metot}

\subsection{Analizde Kullanılan Kimyasallar}

Diklofenak sodyum tuzu (saflık $\geq 98,5)$ Sigma-Aldrich firmasından ve hidrojen peroksit $\mathrm{H}_{2} \mathrm{O}_{2}(\% 35$ saflıkta) Merck, Titanyum dioksit $\left(\mathrm{TiO}_{2}\right)$ (\%99 saflıkta) Merck ve Çinko oksit (ZnO) (\%99 saflıkta) Carlo Erba Reagents firmasından temin edilmiştir. Sentetik su için kullanılan diklofenak ise piyasadan $25 \mathrm{mg} / \mathrm{ml}$ diklofenak konsantrasyonu içeren ampül ilaçtan temin edilmiştir. Diklofenağın ana özellikleri ve yapısı Tablo 1'de verilmiştir. Tüm stok çözeltiler $100 \mathrm{mg} / \mathrm{L}$ konsantrasyonunda saf su ile hazırlanmış ve karanlıkta $+4{ }^{\circ} \mathrm{C}$ 'de muhafaza edilmiştir. 
Tablo 1. Diklofenak'ın fizikokimyasal özellikleri [10, 11]

\begin{tabular}{lc}
\hline \multicolumn{1}{c}{ İlaç } & Diklofenak Sodyum Tuzu \\
\hline CAS No. Kullanım & $15307-79-6$ \\
Molekül Formülü & Analjezik, antienflamatuar \\
Molekül Ağırlığ & $\mathrm{C}_{14} \mathrm{H}_{10} \mathrm{Cl}_{2} \mathrm{NNaO}_{2}$ \\
Suda Çözünürlük & $318,13 \mathrm{~g} / \mathrm{mol}^{-1}$ \\
Log Kow & $2425 \mathrm{mg} / \mathrm{L}\left(25^{\circ} \mathrm{C}\right)$ \\
Buhar Basınc1 & $0,7-4,5(\mathrm{pH}$ 'a bağl $)$ \\
pKa & $4.75^{*} 10^{-14} \mathrm{~mm} \mathrm{Hg}$ \\
Henry Sabiti & 4.15 \\
\hline
\end{tabular}

\subsection{Analizde Kullanılan Çeşme Suyunun Özellikleri}

Tüm giderim çalışmalarında ilaç çözeltileri hazırlamakta kullanılan çeşme suyunun analizleri yapılmıştır. Çeşme suyunun yapılan ilk analiz sonuçları ise Tablo 2'de verilmiştir.

Tablo 2. Çalışmada kullanılan çeşme suyunun özellikleri

\begin{tabular}{lcc}
\hline Parametreler & Birim & Değerler \\
\hline $\mathrm{pH}$ & $\mathrm{pH}$ birimi & 6,98 \\
Toplam çözünmüş madde & $\mu \mathrm{S} / \mathrm{cm}$ & 329 \\
Bulanıklı & $\mathrm{NTU}$ & 1,2 \\
Sicaklık & ${ }^{\circ} \mathrm{C}$ & 19,8 \\
Çözünmüş oksijen & $\mathrm{mg} / \mathrm{L}$ & 7,02 \\
Toplam organik karbon & $\mathrm{mg} / \mathrm{L}$ & 2,02 \\
Toplam azot & $\mathrm{mg} / \mathrm{L}$ & 0,75 \\
Toplam fosfor & $\mathrm{mg} / \mathrm{L}$ & 0,28 \\
\hline
\end{tabular}

\subsection{Deneysel Prosedür ve Hesaplama}

Çalışmada UV reaktörü olarak $50 \mathrm{~Hz}, 220 \mathrm{v}, 254 \mathrm{~nm}$ (UV-C) dalga boyunda 1şık yayan Tetra marka UV reaktörü kullanılmıştır. UV reaktör içerisine, hazırlanan ilaç çözeltileri Watson Marlow marka peristaltik pompa ile iletilmiştir. UV reaktörünün hacmi $500 \mathrm{~cm}^{3}$ olup hidrolik alıkonma süresi 60 dakikadır. Çalışmada sabit $10 \mathrm{rpm}$ hız ve $8,3 \mathrm{ml} / \mathrm{dk}$ debisi ile çözelti UV reaktörüne verilmiştir. İşlem manyetik karıştırıcı eşliğinde gerçekleşmiş ve sistem sürekli olarak 60 dakika boyunca işletilmiştir. Çalışma boyunca pH ile ilgili bir ayarlama yapılmamış, çözeltilerin kendi pH değerinde çalışılmıştır. Ancak prosesin başında ve sonunda düzenli olarak $\mathrm{pH}$ ölçümleri yapılmıştır. Elde edilen veriler $\mathrm{pH}$ değerlerinde önemli bir değişim olmadığını göstermiştir.

Çalışmanın ilk aşamasında; UV reaktörünün tek başına kullanılması ile ilaç giderimi üzerindeki etkisi incelenmiştir. UV reaktör içerisine $500 \mathrm{ml}$ hacmindeki $5 \mathrm{mg} / \mathrm{L}$ diklofenak içeren ilaç çözeltisi 60 dakika süre ile çalıştırılarak UV 1şı̆̆ına tabi tutulmuştur. Bu süre içerisinde daha önceden belirlenen sürelerde (10-20-30-40-50-60 dk), reaktör çıkışından düzenli olarak örnekler alınmıştır. $\mathrm{Bu}$ işlemlerin hepsi manyetik karıştırıcı eşliğinde gerçekleştirilmiştir.

Çalışmanın ikinci aşamasında $\mathrm{UV} / \mathrm{H}_{2} \mathrm{O}_{2}$ prosesi denenmiştir. Çalışma koşulları sadece UV prosesi ile aynı şekilde ayarlanmıştır. Hazırlanan ilaç çözeltilerine derişimleri 50, 100, 200, 400, 800 mg/L olan $\mathrm{H}_{2} \mathrm{O}_{2}, 1000 \mathrm{mg} / \mathrm{L}$ stok çözeltisinden ilave edilmiştir. Bu işlemlerin hepsi manyetik karıştırıcı eşliğinde gerçekleştirilmiştir. 
Çalışmanın üçüncü aşamasında ise, $\mathrm{UV} / \mathrm{TiO}_{2}$ ve $\mathrm{UV} / \mathrm{ZnO}$ prosesleri denemiştir. Çalışma koşulları UV prosesi ile aynı kalmak şartıyla çözeltiye 40, 80, 160, 240, 320mg/L derişimlerini sağlayacak şekilde $\mathrm{TiO}_{2}$ ve $\mathrm{ZnO}, 1000 \mathrm{mg} / \mathrm{L}$ stok çözeltileri kullanılarak çözeltiler hazırlanmıştır. Bu işlemlerin hepsi manyetik karıştırıcı eşliğinde gerçekleştirilmiştir.

Tüm analizler sonucunda Denklem (1)’e göre diklofenak giderim verimleri hesaplanmıştır.

$$
\% \text { Verim }=\frac{c_{0}-c_{e}}{c_{0}} \div 100
$$

Analizi yapılan tüm numunelerin giriş ve çıkış değerleri LC-MS/MS ve TOK cihazları ile ölçülmüş her biri için ayrı ayrı kinetik hesaplaması ve maliyet hesaplamaları yapılmıştır.

\subsection{Analitik Yöntemler}

$\mathrm{Bu}$ çalışmada kullanılan LCMS/MS cihazı (Liquid chromotography-tandem mass spectrometry/ mass spectrometry), Shimadzu LCMS-8040 markadır. Metot belirleme çalışmalarında mobil fazları hazırlamakta metanol, amonyum hidroksit ve ultra saf su kullanılmıştır. Diklofenak için standart maddeden ilk olarak $1000 \mu \mathrm{g} / \mathrm{L}$ derişimlerde stok çözelti hazırlanmıştır. Stok çözeltiden ise gerekli seyrelmeler yapılarak LCMS/MS cihazının ölçüm limitlerine uygun olacak şekilde hazırlanmıştır. Kalibrasyon eğrileri 10-25-50-75-100-150 $\mu \mathrm{g} / \mathrm{L}$ arasında hazırlanmıştır. Kalibrasyonu eğrisinin korelasyon katsayısı 0,99 'dan büyük $\left(\mathrm{R}^{2}>0,99\right)$ olarak hesaplanmıştır. Analizi yapılacak numuneler $0,45 \mu \mathrm{m}$ membran uçlu şırınga filtrelerden geçirilerek LCMS/MS cihazında ölçümleri yapılmıştır.

Tablo 3. Metot doğrulama değerleri

\begin{tabular}{cc}
\hline Metot Doğrulama Değerleri & Diklofenak \\
\hline Regreasyon katsayısı( $\left.\mathrm{R}^{2}\right)$ & 0,9982 \\
LOD (tespit limiti- $\mu \mathrm{g} / \mathrm{L})$ & 0,1612 \\
LOQ (ölçüm limiti- $\mu \mathrm{g} / \mathrm{L})$ & 0,5376 \\
Alıkonma süresi $(\mathrm{dk})$ & 2,452 \\
\hline
\end{tabular}

Diklofenak standardı için LCMS/MS çalışma prensibi: Pozitif modda elektrosprey iyonizasyonlu (ESI) kütle spektrometresinde ölçülmüş kolon olarak ise C18 analitik kolon $(50 \mathrm{mmx} 30 \mathrm{mmx} 2,7 \mu \mathrm{m})$ kullanılmıştır. Gaz sıcaklığı (Ar) $350^{\circ} \mathrm{C}$ 'de $3 \mathrm{~L} / \mathrm{dk}$ akışta ve 660 bar basınçtadır. Taşıyıcı gaz $\left(\mathrm{N}_{2}\right)$ sıcaklığ 1 ise $250^{\circ} \mathrm{C}$ ve $15 \mathrm{~L} / \mathrm{dk}$ akıştadır. Kapiler voltaj ise 4500 volt'tur. Fırın sıcaklığ $40{ }^{\circ} \mathrm{C}$ ve enjeksiyon hacmi ise $20 \mu \mathrm{L}$ 'dir. İyonizasyon modu ESI (+) ve alıkonma süresi 2,452 dk'dir.

Tablo 4. Gradient programı

\begin{tabular}{lccc}
\hline Mikrokirletici & Zaman (dk) & Mobil Faz A (\%) & Mobil Faz B (\%) \\
\hline \multirow{3}{*}{ Diklofenak } & $\mathrm{T}=0$ & 70 & 30 \\
$\left(\% \mathrm{~A} 0,0025 \mathrm{NH}_{4} \mathrm{OH}\right.$ & $\mathrm{T}=1$ & 70 & 30 \\
$\left.\% \mathrm{~B} \mathrm{CH}{ }_{3} \mathrm{OH}\right)$ & $\mathrm{T}=1,5$ & 5 & 95 \\
& $\mathrm{~T}=4,5$ & 5 & 95 \\
& $\mathrm{~T}=4,51$ & 70 & 30 \\
& $\mathrm{~T}=6$ & 70 & 30 \\
\hline
\end{tabular}

UPLC sistem gradient modda A fazı için ultra saf su ve \%0,0025'lik amonyum hidroksit $\left(\mathrm{NH}_{4} \mathrm{OH}\right)$ (v:v: 70:30), B fazı için HPLC derecesinde metanol $\left(\mathrm{CH}_{3} \mathrm{OH}\right)$ (v:v: 70:30) kullanılmıştır. Program B fazı $\% 30$ hacim A fazı $\% 70$ hacim 10 dakika farklı çalıştırma süresi ile 0-1 dk \%70 ultra saf su+0,0025 amonyum hidroksit \%30 hacim metanol, 1-4,5 dk \%5 ultra saf su+0,0025 amonyum 
hidroksit ve $\% 95$ hacim metanol, 4,5-10 dk \%70 hacim ultra saf su+0,0025 amonyum hidroksit ve $\% 30$ hacim metanol verilerek 1,5 ml enjeksiyon hacmi seçilmiştir. Metot doğrulama değerleri Tablo 3'de, Gradient program Tablo 4'te verilmiştir.

TOK ölçümlerinde, Shimadzu TOC V-CPN marka cihazı kullanılmıştır. Analiz metodu ise SM 5310 B seçilmiştir. Seçilen metodun LOD (algılama sınırı) 0,411 mg/L, LOQ (tayin sınırı) 1,37 $\mathrm{mg} / \mathrm{L}$ 'dir.

\section{Bulgular ve Tartışma}

\subsection{Sadece UV Proses ile Diklofenak Giderimi}

İlk olarak diklofenağın sadece UV reaktörü kullanılarak giderim verimi değerlendirilmiştir. Yapılan çalışmada 60 dakikalık işlem süresince farklı çalışma sürelerinde çıkış numuneleri alınarak bu sürelerdeki giderim verimleri değerlendirilmiştir. Sonuçlar Şekil 1'de gösterilmiştir.

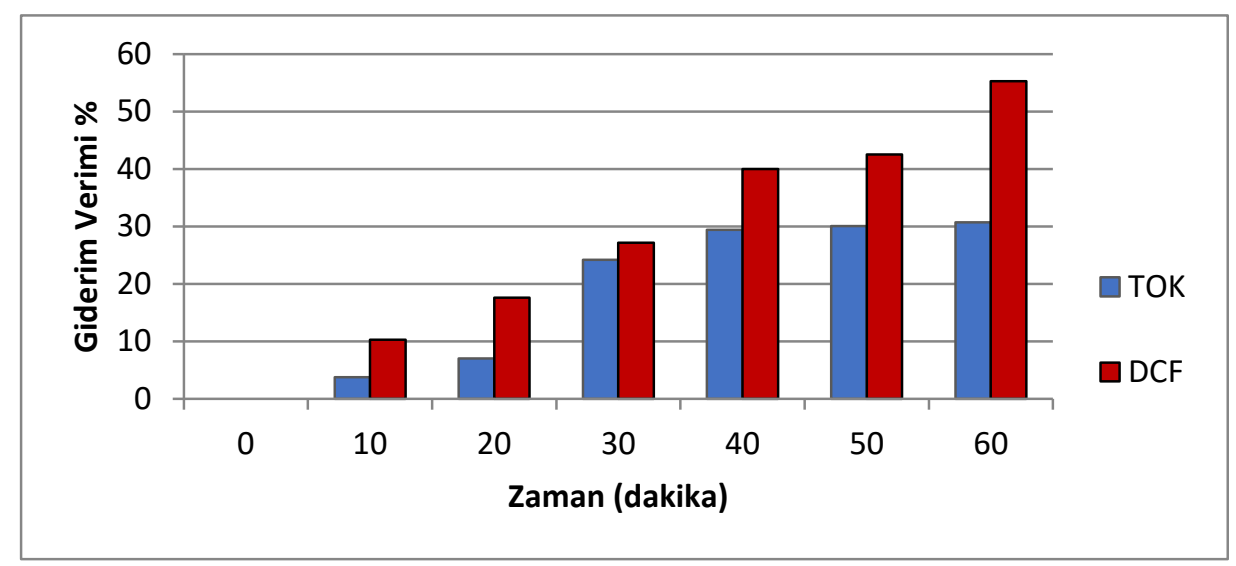

Şekil 1. UV proses ile farklı sürelerde LCMS/MS ve TOK giderimi

Şekil 1'de görüldüğ̈̈ gibi zamana bağlı olarak giderim verimleri artmaktadır. TOK giderimi $\% 30,71$, diklofenak giderimi ise \%55,22 bulunmuştur. UV 1şı̆̆1 kullanılarak gerçekleştirilen reaksiyonların en önemli dezavantajı elektrik tüketiminin fazla olmasıdır [16]. Bu durumda ekonomik açıdan uygun bir işletme koşulu olarak görülmemektedir. Bu bilgiler doğrultusunda tek başına UV kullanımının diklofenak giderimde yeterli olmadığı veya daha uzun proses sürelerine ihtiyaç duyulduğu düşünülmektedir.

\section{2. $\mathrm{UV} / \mathrm{H}_{2} \mathrm{O}_{2}$ Proses ile Diklofenak Giderimi}

Diklofenak giderimi için çalışmanın ikinci aşamasında UV reaktörüne ilave olarak $\mathrm{OH} \bullet$ radikali oluşumunu arttırmak ve dolayısıyla da daha fazla giderim verimi elde etmek için $\mathrm{H}_{2} \mathrm{O}_{2}$ kullanılmıştır. TOK giderim verimleri Şekil 2 ve diklofenak giderim verimleri Şekil 3 'te verilmiştir.

TOK giderim sonuçlarına göre $\mathrm{UV} / \mathrm{H}_{2} \mathrm{O}_{2}$ prosesinin etkinliği $50 \mathrm{mg} / \mathrm{L} \mathrm{H}_{2} \mathrm{O}_{2}$ varlığında ortaya çıkmaktadır. Yalnızca UV ile giderimde 60. dakikanın sonunda verim \%30,71 iken $\mathrm{H}_{2} \mathrm{O}_{2}$ ilavesi ile 10. dakikada bu değer $\% 40$ oranına ulaşmıştır. $50 \mathrm{mg} / \mathrm{L} \mathrm{H}_{2} \mathrm{O}_{2}$ ilavesi sonucu 60 . dakikada verim \%80'e tekâmül etmektedir. $200 \mathrm{mg} / \mathrm{L} \mathrm{H}_{2} \mathrm{O}_{2}$ varlığında tüm süre sonunda verim \%93,57'e ulaşmıştır. 400 ve $800 \mathrm{mg} / \mathrm{L} \mathrm{H}_{2} \mathrm{O}_{2}$ ilavesinde yaklaşık \%98 oranında TOK giderim verimleri elde edilmiştir. TOK giderim çalışması ile diklofenak ilacı dışında organik maddelerin ne kadar giderildiği de tespit edilmiştir. Giri ve ark. [17], laboratuvar ortamında yaptıkları çalışmada, analiz sonuçlarında 
diklofenak için $\mathrm{H}_{2} \mathrm{O}_{2}$ ilavesiyle kısa reaksiyon sürelerinde çok verimli bir şekilde bozunma sağladıklarını gözlemlemişlerdir.

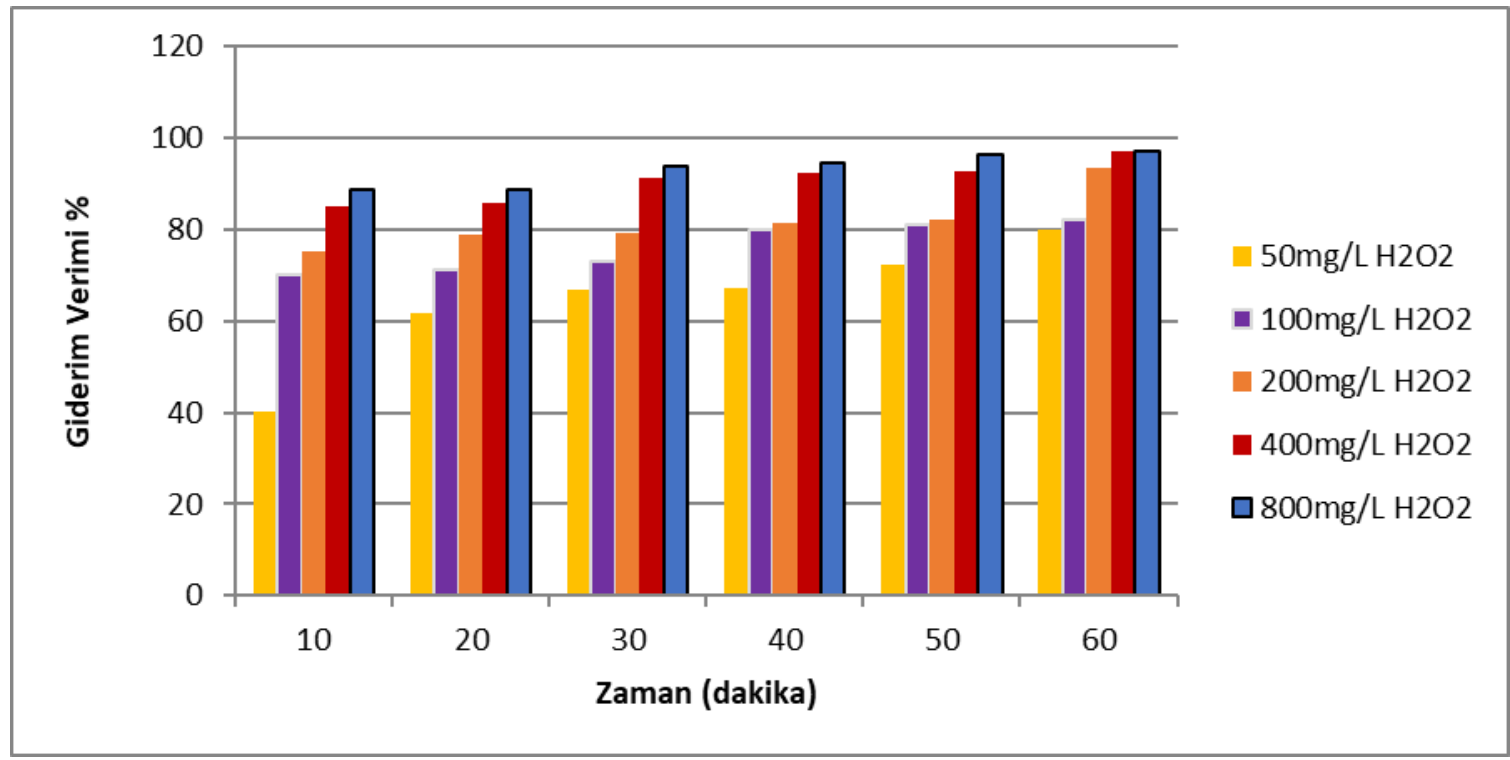

Şekil 2. $\mathrm{UV} / \mathrm{H}_{2} \mathrm{O}_{2}$ proses ile farklı sürelerde TOK giderimi

Şekil 3'te görüldügü üzere $U V / \mathrm{H}_{2} \mathrm{O}_{2}$ proseslerinde $\mathrm{H}_{2} \mathrm{O}_{2}$ derişimi arttıkça diklofenak giderim verimi de daha kısa sürede daha yüksek değerler almaktadır. Analiz sonuçları incelendiğinde tüm reaksiyon süresi sonunda 50 ve $100 \mathrm{mg} / \mathrm{L} \mathrm{H}_{2} \mathrm{O}_{2}$ derişimleri ile diklofenağın tamamen giderilemediği tespit edilmiştir.

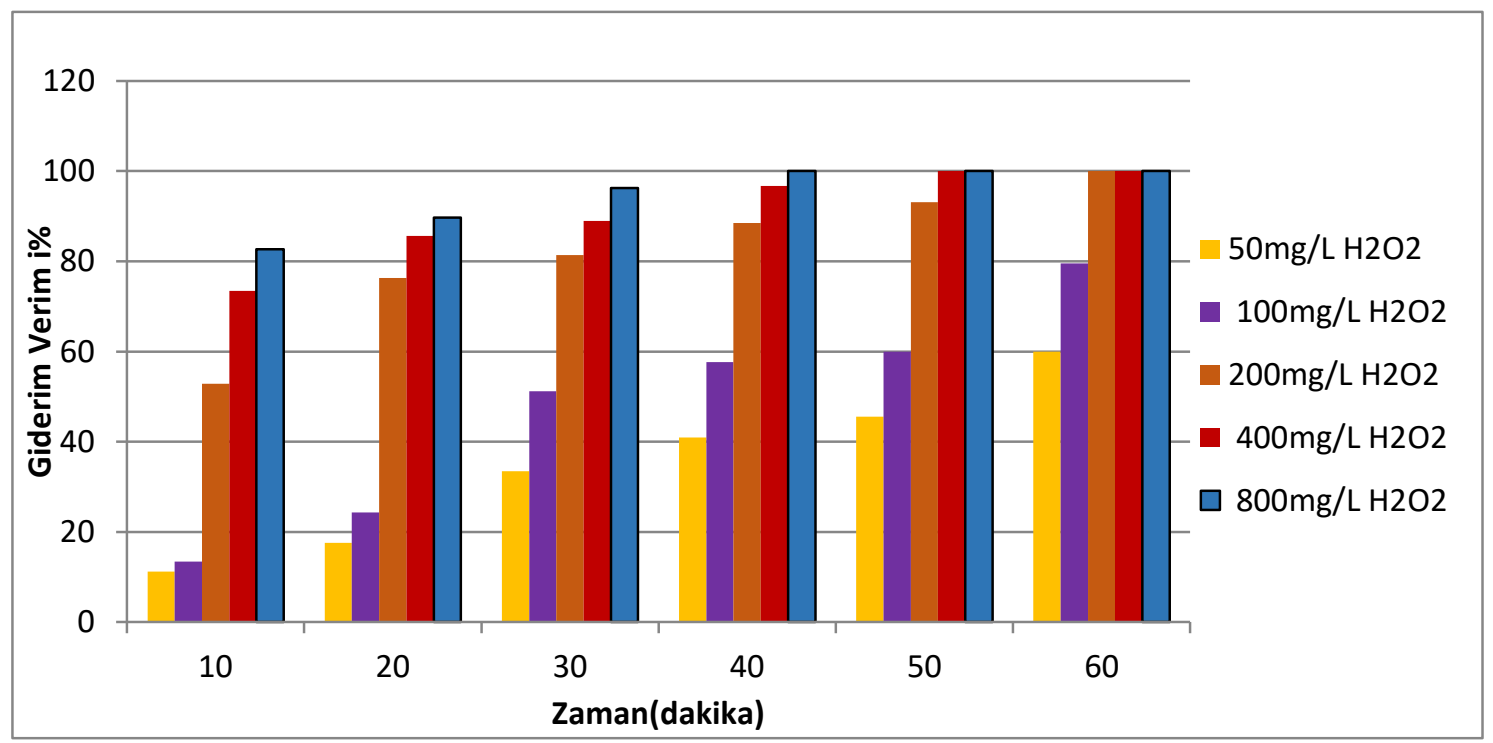

Şekil 3. $\mathrm{UV} / \mathrm{H}_{2} \mathrm{O}_{2}$ proses ile farklı sürelerde Diklofenak giderim verimleri

$50 \mathrm{mg} / \mathrm{L} \mathrm{H}_{2} \mathrm{O}_{2}$ varlığında verim \%60'a, $100 \mathrm{mg} / \mathrm{L}$ 'de ise \%80'e yaklaştı̆̆ 1 görülmektedir. Ancak $200 \mathrm{mg} / \mathrm{L} \mathrm{H}_{2} \mathrm{O}_{2}$ varlığında 60.dakikada, $400 \mathrm{mg} / \mathrm{L} \mathrm{H}_{2} \mathrm{O}_{2}$ varlığında 50. dakikada, $800 \mathrm{mg} / \mathrm{L}$ 'de ise 40.dakikada diklofenağın tamamının giderildiği görülmektedir. Buradaki amaç, olabildiğince az kimyasal madde kullanıp kısa sürede yüksek giderim verimi elde etmektir.

Kim ve ark. [18], yaptıkları bir çalışmada; UV yöntemiyle arıtım sırasında farmasötiklerin foto bozunması ile ilgili $\mathrm{H}_{2} \mathrm{O}_{2}$ ilavesinin etkisini araştırmışlardır. UV arıtımına $\mathrm{H}_{2} \mathrm{O}_{2}$ ilave etmek 
suretiyle farmasötiklerin bozunmasının arttığı tespit edilmiştir. Yine Vogna ve ark. [1], yaptıkları bir başka çalışmada, $\mathrm{H}_{2} \mathrm{O}_{2} / \mathrm{UV}$ sistemlerinin diklofenak parçalanmasının başlamasında etkili olduğunu vurgulamışlardır. Çalışmamızın analiz sonuçları, bu çalışmalarla benzerlik göstermiş olup UV sitemine $\mathrm{H}_{2} \mathrm{O}_{2}$ ilave edilmesi hem TOK hem de diklofenak giderim verimlerini olumlu etkilemiştir.

\subsection{UV/TiO 2 Proses ile Diklofenak Giderimi}

Çalışmanın bu bölümündeki amaç, UV ışığı kombinasyonu ile $\mathrm{TiO}_{2}$ fotokatalizörünün Diklofenak giderimi üzerindeki etkinliğini belirlemektir. TOK giderimi Şekil 4 ve Diklofenak giderimi Şekil 5 'te verilmiştir.

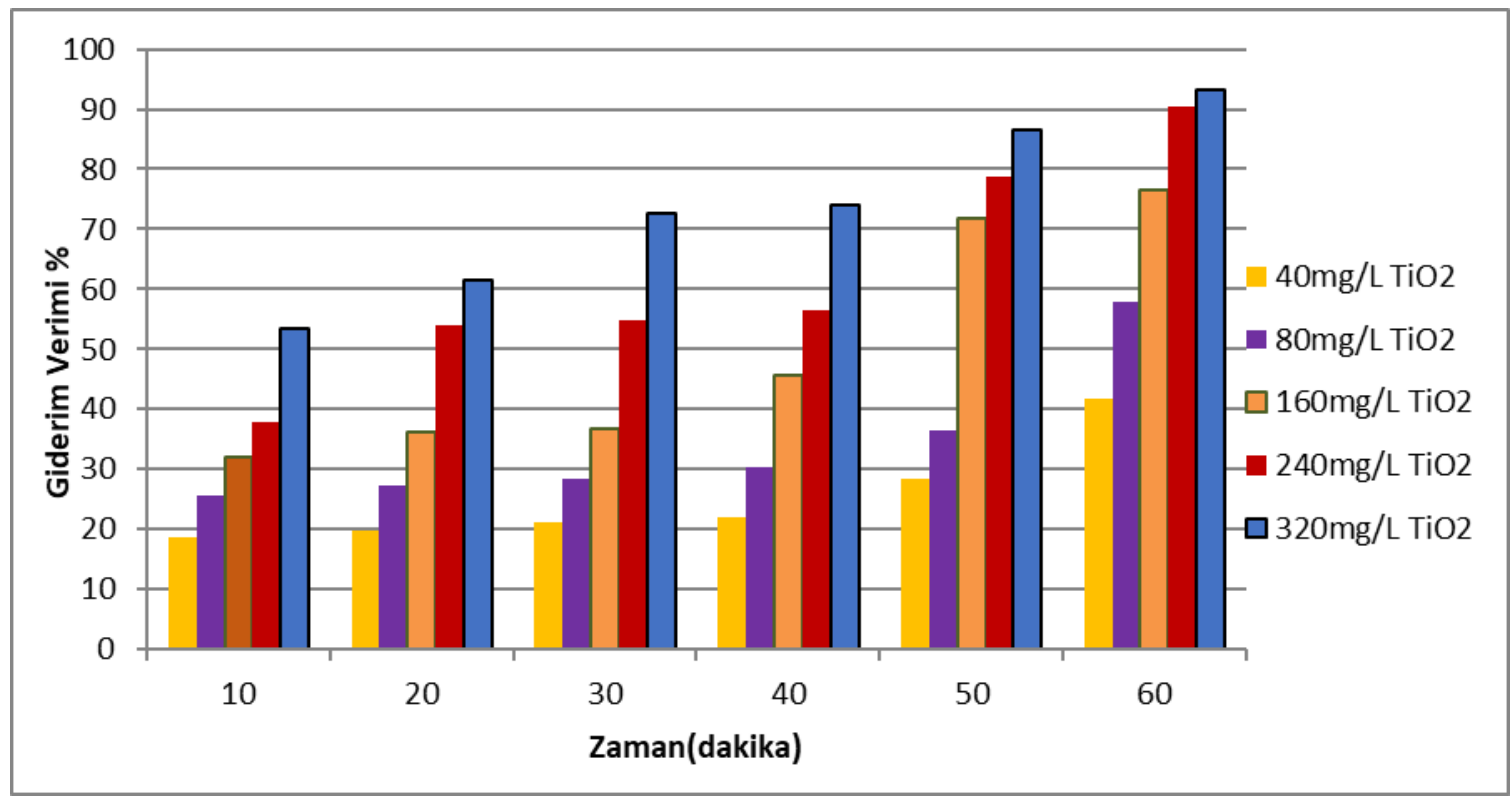

Şekil 4. UV/TiO 2 proses ile farklı sürelerde TOK giderimi

Şekilde gösterildiği gibi yapılan deneyde $\mathrm{TiO}_{2}$ konsantrasyonu arttığında giderim TOK giderim verimi artış göstermektedir. $40 \mathrm{mg} / \mathrm{L}$ ile başlanan $\mathrm{TiO}_{2}$ ilavesi $320 \mathrm{mg} / \mathrm{L}$ ye kadar çıkarılmıştır ve orantılı olarak TOK gideriminin de arttığı gözlenmiştir. TOK gideriminde en yüksek değer 320 $\mathrm{mg} / \mathrm{L} \mathrm{TiO}_{2}$ konsantrasyonunda 60 dakika süre sonunda \%93 olarak gözlenmiştir. Pérez-Estrada ve ark. [19], yaptıkları çalışmada diklofenağın pH 3'te yapılan analiz sonuçlarında 3 saat içinde TOK giderimini $\% 90$ olarak tespit etmişlerdir. Analiz sonuçları $\mathrm{TOK}$ giderimine, $\mathrm{TiO}_{2}$ konsantrasyonun etki ettiği ve konsantrasyon arttıkça giderim veriminin de arttığını göstermektedir.

Şekil 5'te 60 dakikalık süre sonunda tüm değerler için diklofenak giderim verimleri \%90'ın üzerinde olduğu görülmektedir. $240 \mathrm{mg} / \mathrm{L} \mathrm{TiO}_{2}$ konsantrasyonu ile 60. dakika sonunda ve $320 \mathrm{mg} / \mathrm{L}$ $\mathrm{TiO}_{2}$ konsantrasyonu kullanımı ile 50. dakika sonunda diklofenağın tamamen giderimi gerçekleşmiştir. Ekonomik açıdan sürenin mi yoksa $\mathrm{TiO}_{2}$ konsantrasyonun mu fazla kullanması daha faydalı olacağının tespiti için maliyet analizi yapılmıştır. Maliyet analizi sonucuna göre 240mg/L'den daha fazla $\mathrm{TiO}_{2}$ kullanılmasının giderim verimi açısından daha fazla bir yarar sağlamayacağı da tespit edilmiş ve cihazın 10 dakika daha fazla çalıştırılmasının uygun olacağına karar verilmiştir.

Benitez ve ark. [20], ilaçların farklı kimyasal arıtım yöntemleri ile bozunmalarını inceledikleri çalışmada $\mathrm{UV} / \mathrm{TiO}_{2}$ prosesi ile en yüksek giderim verimleri tespit etmişlerdir [20]. Yine Sarasidis ve ark. [21] yaptıkları başka bir çalışmada, diklofenak gideriminde $\mathrm{UV} / \mathrm{TiO}_{2}$ prosesi ile $500 \mathrm{mg} / \mathrm{L}$ $\mathrm{TiO}_{2}$ konsantrasyonu ilavesi ile diklofenağın giderim veriminin \%99 olarak tespit etmişlerdir. 
Ahmed ve ark. [22], yaptıkları bir diğer çalışmada ise, diklofenağın de içinde bulunduğu üç ilacın $\mathrm{UV} / \mathrm{TiO}_{2}$ oksidasyonu ile arıtımını araştırmışlardır. İncelenen tüm bileşikler için \% $50 \mathrm{TOK}$ giderim veriminin elde edildiğini bildirmişlerdir. Tokumura ve ark. [23] yaptıkları çalışmada ise $\mathrm{UV} / \mathrm{TiO}_{2}$ kombinasyonu ile atık su matrisindeki ilaçların önemli ölçüde giderildiğini bildirmişlerdir. Ayrıca, diklofenak giderim veriminin \%55,6-94,4 arasında olduğunu tespit etmişlerdir.

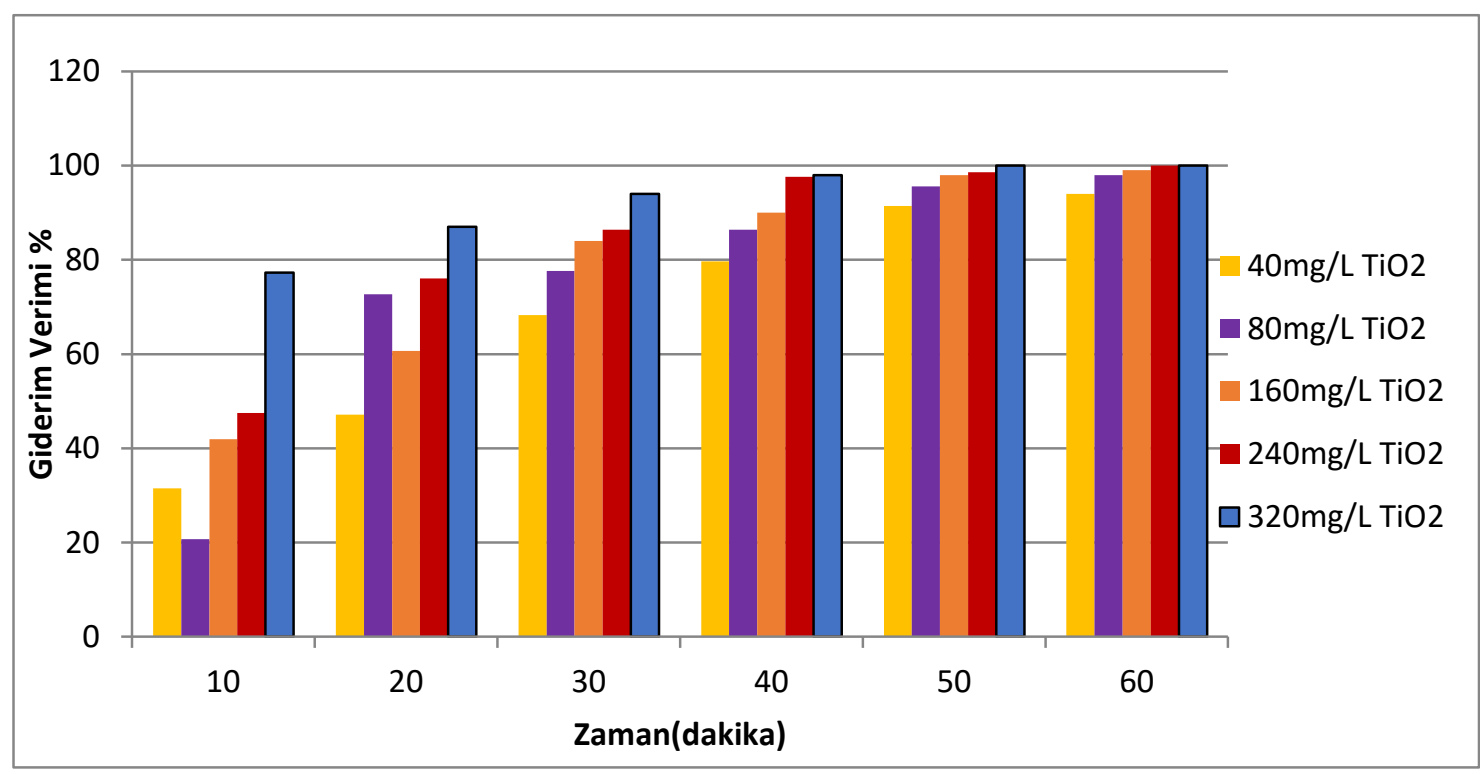

Şekil 5. UV/ $\mathrm{TiO}_{2}$ proses ile farklı sürelerde Diklofenak giderim verimleri

Tokumura et al. (2016) yaptıkları çalışmada ise $\mathrm{UV} / \mathrm{TiO}_{2}$ kombinasyonu ile atık su matrisindeki ilaçların önemli giderildiğini bildirmişlerdir. Aryıca, Diklofenak giderim veriminin \%55,6-94,4 arasında olduğunu tespit etmişlerdir [19].

\subsection{UV/ZnO Proses ile Diklofenak Giderimi}

Çalışmanın bu bölümde ise bir başka fotokatalizör olan $\mathrm{ZnO}$ ile UV kombinasyonu denenmiş ve diklofenağın giderim verimi belirlenmiştir. TOK giderimi Şekil 6 ve DCF giderimi Şekil 7'de verilmiştir.

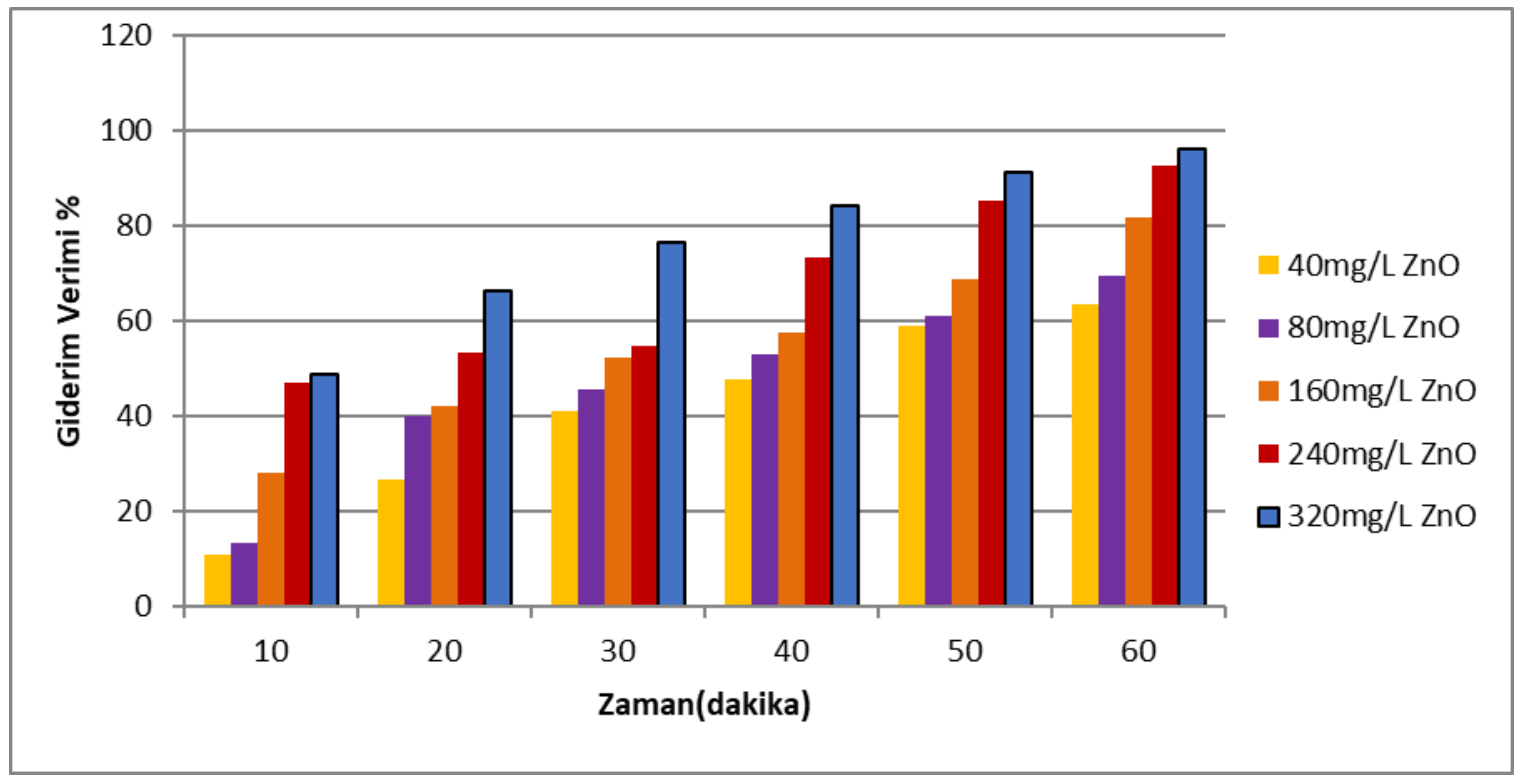

Şekil 6. UV/ZnO proses ile farklı sürelerde TOK giderimi 
Çalışmada ilk olarak TOK giderim verimleri incelenmiş ve $\mathrm{ZnO}$ konsantrasyonu arttıkça giderim veriminin de artış gösterdiği tespit edilmiștir. 40, 80, 160, 240 ve $320 \mathrm{mg} / \mathrm{L} \mathrm{ZnO}$ konsantrasyonları için 60 dakika sonundaki giderim verimleri sırasıyla; \% 63,33, 69,52, 81,74, 92,41 ve 96,10 olarak bulunmuştur. Sonuçlar incelendiğinde en yüksek TOK giderim verimi $320 \mathrm{mg} / \mathrm{L}$ konsantrasyonu ile elde edilmiştir.

Yapılan benzer literatür çalışmalarında ise ilaç kalıntı üzerinde $\mathrm{ZnO}$ yarı katalizörünün TOK giderim verimi incelendiğinde verime olumlu yönde etki ettiği tespit edilmiştir. Ong ve ark. [24] kalıcı organik kirleticiler üzerine yaptığı çalışmada, en yüksek spesifik yüzey alanına sahip olan ZnO'nun en yüksek giderim verimi sağladığını bildirmişlerdir. Karaca ve ark. [25], tarafindan yapılan başka bir çalışmada ise montmorillonit destekli $\mathrm{ZnO}$ katalizör ile gerçekleştirilen naproksenin katalitik oksidasyon reaksiyonunda da gözlenmiş, TOK gideriminin $\mathrm{ZnO}$ derişimi ile arttı̆̆ını tespit etmişlerdir.

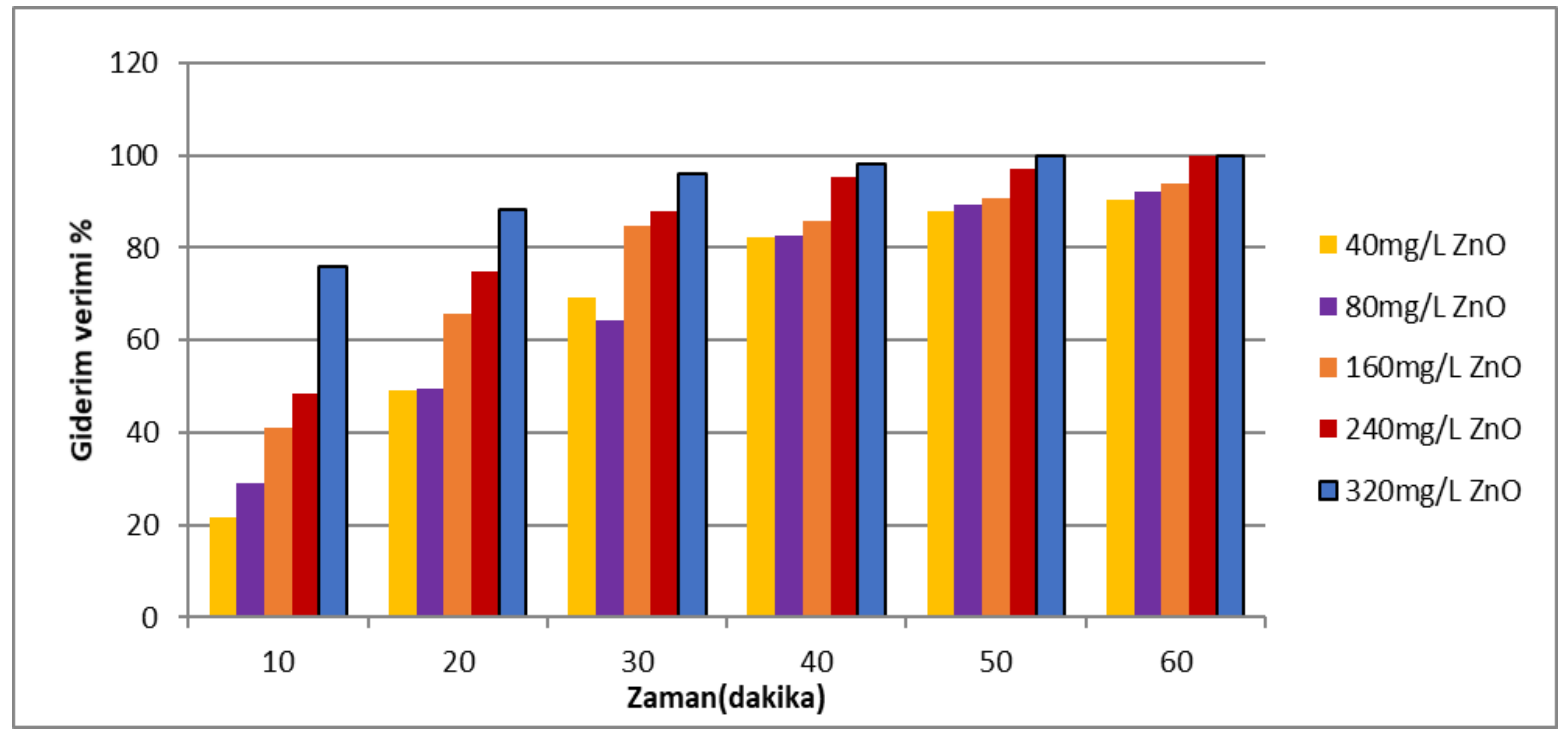

Şekil 7. UV/ZnO proses ile farklı sürelerde DCF giderim verimleri

Çalışma diklofenak giderim verimi incelendiğinde, $40 \mathrm{mg} / \mathrm{L} \mathrm{ZnO}$ konsantrasyonunda \%90,32 ve $160 \mathrm{mg} / \mathrm{L} \mathrm{ZnO}$ konsantrasyonunda ise 50. dakikada \%90,86 giderim verimi tespit edilmiştir. 240mg/L ZnO konsantrasyonu ile 60. dakikada ve $320 \mathrm{mg} / \mathrm{L} \mathrm{ZnO}$ konsantrasyonu ile ise 50. dakikada diklofenağın tamamen giderildiği tespit edilmiştir. Madhavan ve ark. [26] yaptıkları benzer bir çalışmada, sulu ortamda bulunan diklofenağın bozunmasını üç fotokatalist $\left(\mathrm{TiO}_{2}, \mathrm{ZnO}\right.$ ve Fe-ZnO) kullanarak incelemişler ve $\mathrm{UV} / \mathrm{ZnO}$ kombinasyonun diklofenak DCF giderimde etkili olduğunu belirtmişlerdir.

\subsection{Kinetik Çalışmalar}

Diklofenak ilacının sadece $\mathrm{UV}, \mathrm{UV} / \mathrm{H}_{2} \mathrm{O}_{2}, \mathrm{UV} / \mathrm{TiO}_{2}$ ve $\mathrm{UV} / \mathrm{ZnO}$ prosesleri ile giderim verimleri belirlenmiş ve tüm konsantrasyon değerleri için sıfırıncı, birinci ve ikinci derece reaksiyon

Tablo 5. Diklofenak ile ilgili optimum kinetik analiz sonuçları

\begin{tabular}{lcccccc}
\hline \multirow{2}{*}{ Prosesler } & \multicolumn{2}{c}{ 0.derece } & \multicolumn{2}{c}{ 1.derece } & \multicolumn{2}{c}{ 2.derece } \\
\cline { 2 - 7 } & $\mathbf{R}^{\mathbf{2}}$ & $\mathbf{k}$ & $\mathbf{R}^{\mathbf{2}}$ & $\mathbf{k}$ & $\mathbf{R}^{\mathbf{2}}$ & $\mathbf{k}$ \\
\hline Sadece $\mathrm{UV}$ & $\mathbf{0 , 9 8}$ & $\mathbf{0 , 0 6}$ & 0,97 & 0,01 & 0,93 & $3 * 10^{-6}$ \\
$\mathrm{UV} / 200 \mathrm{mg} / \mathrm{L} \mathrm{H}_{2} \mathrm{O}_{2}$ & 0,77 & 0,09 & $\mathbf{0 , 9 7}$ & $\mathbf{0 , 0 5}$ & 0,90 & 0,03 \\
$\mathrm{UV} / 320 \mathrm{mg} / \mathrm{L} \mathrm{TiO}_{2}$ & 0,58 & 0,06 & $\mathbf{0 , 9 7}$ & $\mathbf{0 , 0 9}$ & 0,76 & 0,22 \\
$\mathrm{UV} / 240 \mathrm{mg} / \mathrm{L} \mathrm{ZnO}$ & 0,78 & 0,08 & $\mathbf{0 , 9 9}$ & $\mathbf{0 , 0 7}$ & 0,85 & 0,11 \\
\hline
\end{tabular}


kinetikleri incelenmiştir. Kinetik çalışmasında, diklofenak için optimum sonuçlar dikkate alınmıştır. Tablo 5'te kinetik sonuçları kalın punto ile yazılmıştır. Bu sonuçlara göre, sadece UV prosesi sıfırınc1 dereceden, diğer prosesler ise birinci dereceden kinetik modeline uygun olduğu tespit edilmiştir.

\subsection{Maliyet Analizi}

Çalışma sonucunda her prosesin optimum değerlerini belirlemek için maliyet hesaplaması yapılmıştır. Hesaplamalar yapılırken, proseslerde kullanılan UV reaktörünün elektrik tüketimi ve kullanılan kimyasalların sarfiyatları göz önüne alınmıştır. Maliyet hesabı ile ilgili cihaz verileri: reaktördeki UV lambasının saatlik elektrik enerjisi sarfiyatı 16 watt, peristaltik pompanın sarfiyatı ise 100 watt'tır. Elektrik birim fiyat $1 \mathrm{kWh}$ 'i 53,57 kuruştur [27]. Kimyasalların fiyatları ise $\mathrm{H}_{2} \mathrm{O}_{2}$ kimyasalının litre fiyatı 43,00 TL, $\mathrm{TiO}_{2}$ kimyasalının kilogram fiyatı 1.470,00 TL ve $\mathrm{ZnO}$ kimyasalının kilogram fiyatı 280,00 TL olarak hesaplanmıştır. Hesaplamalar, sistemin atıksu arıtma tesislerine uygulanması planlandığı için metreküp $\left(\mathrm{m}^{3}\right)$ cinsinden yapılmıştır. Maliyet analizi sonuçları Tablo 6'da verilmiştir.

Tablo 6. Diklofenak maliyet analizleri

\begin{tabular}{|c|c|c|c|c|c|}
\hline Prosesler & $\begin{array}{c}\text { Optimum } \\
\text { Giderim verimi \% }\end{array}$ & $\begin{array}{l}\text { Optimum } \\
\text { Süre dk }\end{array}$ & $\begin{array}{c}\text { Maliyet TL } \\
\text { E }\end{array}$ & $\underset{\$}{\text { Dolar }}$ & $\underset{€}{\text { Euro }}$ \\
\hline Sadece UV & 55,23 & 60 & 124 & 21,64 & 19,43 \\
\hline $\mathrm{UV} / 200 \mathrm{mg} / \mathrm{L} \mathrm{H}_{2} \mathrm{O}_{2}$ & $>99,99$ & 60 & 168 & 29,31 & 26,33 \\
\hline $\mathrm{UV} / 400 \mathrm{mg} / \mathrm{L} \mathrm{H}_{2} \mathrm{O}_{2}$ & $>99,99$ & 50 & 190 & 33,15 & 29,78 \\
\hline $\mathrm{UV} / 800 \mathrm{mg} / \mathrm{L} \mathrm{H}_{2} \mathrm{O}_{2}$ & $>99,99$ & 40 & 254,80 & 44,46 & 39,93 \\
\hline $\mathrm{UV} / 240 \mathrm{mg} / \mathrm{L} \mathrm{TiO}_{2}$ & $>99,99$ & 60 & 828 & 144,50 & 129,80 \\
\hline $\mathrm{UV} / 320 \mathrm{mg} / \mathrm{L} \mathrm{TiO}{ }_{2}$ & $>99,99$ & 50 & 1043,8 & 182,16 & 163,60 \\
\hline $\mathrm{UV} / 240 \mathrm{mg} / \mathrm{L} \mathrm{ZnO}$ & $>99,99$ & 60 & 258,40 & 45,09 & 40,50 \\
\hline $\mathrm{UV} / 320 \mathrm{mg} / \mathrm{L} \mathrm{ZnO}$ & $>99,99$ & 50 & 283 & 49,38 & 44,35 \\
\hline
\end{tabular}

Maliyet analizi sonucuna göre $\mathrm{UV} / \mathrm{H}_{2} \mathrm{O}_{2}$ prosesi için $200 \mathrm{mg} / \mathrm{L}, \mathrm{UV} / \mathrm{TiO}_{2}$ prosesi için $240 \mathrm{mg} / \mathrm{L}$ ve $\mathrm{UV} / \mathrm{ZnO}$ prosesi için ise $240 \mathrm{mg} / \mathrm{L}$ konsantrasyonları optimum olarak bulunmuştur. Optimum proses seçimi ise sadece UV prosesinde diklofenağın tamamı giderilemediği için UV kombinasyonları $\left(\mathrm{H}_{2} \mathrm{O}_{2}, \mathrm{TiO}_{2}\right.$ ve $\left.\mathrm{ZnO}\right)$ arasında belirlenmiştir. Maliyet hesaplamasına göre optimum proses $\mathrm{UV} / \mathrm{H}_{2} \mathrm{O}_{2}$ prosesi seçilmiştir.

\section{Sonuçlar}

İlaç kalıntılarının sucul ortamlarda bulunması hem canlılar hem de çevre için endişe verici bir çevre sorunu haline gelmektedir. Çalışmada günümüzde içme sularına kadar ulaşmış olan ve konvansiyonel arıtma yöntemleri ile giderimi gerçekleştirilemeyen diklofenak mikrokirleticisinin ileri oksidasyon yöntemlerinden ultraviyole sistemler ile giderimi incelenmiştir.

Yapılan analizler sonucunda sadece UV prosesinin diklofenağın tamamının gideriminde etkili olmadığ1 sonucuna varılmıştır. Hidroksil oluşumunu arttırmak için UV sistemine $\mathrm{H}_{2} \mathrm{O}_{2}$ ilavesi yapılarak gerçekleştirilen analizde optimum $\mathrm{H}_{2} \mathrm{O}_{2}$ konsantrasyonu $200 \mathrm{mg} / \mathrm{L}$ bulunmuş ve bu değerde diklofenağın tamamı giderilmiştir. Çalışmada ayrıca diklofenağın fotokatalatik bozunması incelenmiş ve bu amaçla $\mathrm{TiO}_{2}$ ve $\mathrm{ZnO}$ etkinliği araştırılmıştır. Bunun sonucunda her iki yarı iletken içinde $240 \mathrm{mg} / \mathrm{L}$ konsantrasyon optimum değer olarak bulunmuş ve bu değerde diklofenağın tamamının giderildiği tespit edilmiştir. Analizler tamamlandıktan sonra tüm proseslerin optimum değerleri için maliyet hesaplaması yapılmış ve maliyet açısından $\mathrm{UV} / \mathrm{H}_{2} \mathrm{O}_{2}$ prosesi optimum proses olarak belirlenmiştir. Çalışma sonunda UV ışı̆̆ı altında diklofenağın parçalanabilirliğinin kolay 
olduğu tespit edilmiştir ve bu nedenle atıksu arıtma tesislerinin giriş kısımlarına veya dördüncül basamak olarak son kısımlarına uygulanabilmesi önerilmektedir. Bu sistemin en önemli dezavantajı ise UV lambasının ömrü ve elektrik enerjisinin oluşturacağı maliyettir. Bu nedenle paket arıtım yapan küçük ölçekli bölgelerde kullanımının ideal olduğu düşünülmektedir.

\section{Kaynaklar}

[1]. Vogna, D., Marotta, R., Napolitano, A., Andreozzi, R. and D'lschia, M., Advanced Oxidation of The Pharmaceutical Drug Diclofenac with $\mathrm{UV} / \mathrm{H}_{2} \mathrm{O}_{2}$ and Ozone. Water Research, 2004, 38(2), 414-422.

[2]. Şahan, A., Farmasötik Maddelerin Aktif Çamur Arıtma Prosesinde Abiyotik Gideriminin İncelenmesi, Çukurova Üniversitesi Fen Bilimleri Enstitüsü, 2007, Adana, 90.

[3]. Kümmerer, K., Pharmaceuticals in the Environment. Annual Review of Environment and Resources, 2010, 35, 57-75.

[4]. Schwaiger, J., Ferling, H., Mallow, U., H. Wintermayr, H. and Negele, R.D., Toxic Effects of the Non-Steroidal Anti-Inflammatory Drug Diclofenac Part I: Histopathological Alterations and Bioaccumulation in Rainbow Trout. Aquatic Toxicology, 2004, 68, 141-150.

[5]. Lee, J., Ji, K., Kho, Y. L., Kim, P. and Choi, K., Chronic Exposure to Diclofenac On Two Freshwater Cladocerans and Japanese Medaka. Ecotoxicology and Environmental Safety, 2011, 74(5), 1216-1225.

[6]. Afonso-Olivares, C., Sosa-Ferrera, Z., Santana-Rodríguez J.J., Occurrence and environmental impact of pharmaceutical residues from conventional and natural wastewater treatment plants in Gran Canaria (Spain), Science of the Total Environment, 2017, 599-600, 934-943.

[7]. Shraim, A., Diab, A., Alsuhaimi, A., Niazy, E., Metwally, M., Amad, M., Sioud, S., Dawoud, A., Analysis of some pharmaceuticals in municipal wastewater of Almanawarah, Arabian Journal of Chemistry, 2017, 10, 719-729.

[8]. Yerüstü Su Kalitesi Yönetmeliği. RG Tarihi:10.8.2016, R.G. Sayıs1:29797 Çevre ve Şehircilik Bakanlığ 1 , Ankara.

[9]. Yang, J. F., Ying, G. G., Zhao, J. L., Tao, R., Su, H. C. and Chen, F., Simultaneous Determination of Four Classes of Antibiotics in Sediments of the Pearl Rivers Using RRLCMS/MS, Science of the Total Environment, 2010, 408(16), 3424-3432.

[10]. Mirzaei, A., Chen, Z., Haghighat, F., Yerushalmi, L., Removal of pharmaceuticals from water by homo/heterogonousFenton-type processes;A review, Chemosphere, 2017, 174, 665-688.

[11]. Yang, J. F., Ying, G. G., Zhao, J. L., Tao, R., Su, H. C. and Chen, F., Simultaneous determination of four classes of antibiotics in sediments of the Pearl rivers using RRLCMS/MS, Science of the Total Environment, 2010, 408(16), 3424-3432.

[12]. Ince, N. H. and Apikyan, I. G., Combination of Activated Carbon Adsorption with Light Enhanced Chemical Oxidation Via Hydrogen Peroxide. Water Research, 2000, 34.17, 41694176.

[13]. Jiang, J., Zhou, Z. and Sharma, V. K., Occurrence, Transportation, Monitoring and Treatment of Emerging Micro-Pollutants in Wastewater. A Review from Global View, Microchemical Journal, 2013, 110, 292-300.

[14]. Environmental Health Analysis, Scientific Databases. http://esc.srcinc.com/fatepointer/search.asp. (Erişim tarihi: 10.05.2020)

[15]. Epold I., Dulova N., Trapido M. 2012. Degradation of Diclofenac in Aqueous Solution by Homogeneous and Heterogeneous Photolysis, Journal of Environmental Engineering and Ecological Science, http://dx.doi.org/10.7243/2050-1323-1-3.

[16]. Çatalkaya E.Ç., Bali U., Şengül F., Fenol'ün Fotokimyasal Yöntemlerle Parçalanması ve Mineralizasyonu, Su Kirlenmesi ve Kontrolü Dergisi, 2004, 14(3), 31 -41.

[17]. Giri, R. R., Ozaki, H., Ota, S., Takanami, R. and Taniguchi, S., Degradation of Common Pharmaceuticals and Personal Care Products in Mixed Solutions by Advanced Oxidation 
Techniques. International Journal of Environmental Science and Technology, 2010, 7(2), 251260.

[18]. Kim, I., Yamashita, N. and Tanaka, H., Photodegradation of Pharmaceuticals and Personal Care Products During UV and UV/ $\mathrm{H}_{2} \mathrm{O}_{2}$ Treatments. Chemosphere, 2009a, 77, 518-524.

[19]. Pérez-Estrada, L. A., Maldonado, M. I., Gernjak, W., Agüera, A., Fernández-Alba, A. R., Ballesteros, M. M. and Malato, S., Decomposition of Diclofenac by Solar Driven Photocatalysis at Pilot Plant Scale. Catalysis Today, 2005, 101(3-4), 219-226.

[20]. Benitez, F.J., Acero, J.L., Real, F.R., Roldan, G. and Casas, F., Comparison of Different Chemical Oxidation Treatments for The Removal of Selected Pharmaceuticals in Water Matrices. Chemical Engineering Journal, 2011, 168, 1149-1156.

[21]. Sarasidis, V.C., Plakas, K.V., Patsios, S.I. and Karabelas, A.J., Investigation of Diclofenac Degradation in A Continuous Photo-Catalytic Membrane Reactor. Influence of Operating Parameters. Chemical Engineering Journal, 2014, 239, 299-311.

[22]. Ahmed, M. M., Brienza, M., Goetz, V. and Chiron, S., Solar Photo-Fenton Using Peroxymonosulfate for Organic Micropollutants Removal from Domestic Wastewater: Comparison with Heterogeneous $\mathrm{TiO}_{2}$ Photocatalysis. Chemosphere, 2014, 117, 256-261.

[23]. Tokumura, M., Sugawara, A., Raknuzzaman, M., Habibullah-Al-Mamun, M. and Masunaga, S., Comprehensive Study on Effects of Water Matrices on Removal of Pharmaceuticals by Three Different Kinds of Advanced Oxidation Processes. Chemosphere, 2016, 159, 317-325.

[24]. Ong, C.B., Ng, L.Y. and Mohammad, A.W., A Review of ZnO Nanoparticles as Solar Photocatalysts: Synthesis, Mechanisms and Applications. Renewable and Sustainable Energy Reviews, 2018, 81, 536-551.

[25]. Karaca, M., Kıranşan, M., Karaca, S., Khataee, A. and Karimi, A., Sonocatalytic Removal of Naproxen by Synthesized Zinc Oxide Nanoparticles on Montmorillonite. Ultrasonics Sonochemistry, 2016, 31: 250-256.

[26]. Madhavan, J., Kumar, P.S.S., Anandan, S., Zhou, M., Grieser, F. and Ashokkumar, M., Ultrasound Assisted Photocatalytic Degradation of Diclofenac in An Aqueous Environment. Chemosphere, 2010, 80(7), 747-752.

[27]. https://www.enerjiatlasi.com/elektrik-fiyatlari/ (Erişim tarihi: 10.05.2020) 